\title{
Food Facts, Nutrients and Immunity System for COVID-19 Prevention
}

\author{
Rokayya Sami ${ }^{1}$, Jingwen $\mathrm{Xu}^{1}$, Fuguo $\mathrm{Jia}^{1}$, and Yang $\mathrm{Li}^{1}$ \\ ${ }^{1}$ Northeast Agricultural University
}

May 11, 2020

\begin{abstract}
The world is in front of a risky epidemic due to novel coronavirus (2019-CoV or COVID-19). This virus is not only affected human health but it affected the economy and caused completely paralysis in many countries of the world. Various therapeutic, medicinal, scientific, and technological communities are demanding to find out specifically and to approve successful strategies for discovering the effective vaccine which can lead to stop the virus expansion, recognize medication, reduce humanity health hazards, serious infections, death rates. The importance of natural effective nutritious food and diet having peculiar immunity is highlighted which pointed out the unconfirmed dietary option risks which would lead to decline effective precautionary procedures. This report is aimed to focus on the most effective food and nutrients which trigger the body immunity system and prevent the coronavirus type infections.
\end{abstract}

\section{General Treatment For Viral Infection}

\subsection{Essential Facts}

There are following essential facts which are involved in treatment; (1) Effective immunity system is gained in result of regular processes of healthy food within (1-4) months, (2) Effective immunity system occurs as a result of getting (3-4) types of healthy food daily, (3) Maintaining safety procedures, sterilization and avoiding crowded places protects from COVID-19 infection, (4) Need of sufficient sleep, the body can make fewer cytokines which boost immunity against diseases, and (5) Ordinary moderate exercise reported fewer colds temporary boost in macrophages production.

\subsubsection{Nigella sativa seed oil}

$N$. sativa seed oil contain highly dose of thymoquinone, thymol, dithymoquinone, carvacrol, nigellimine-Noxide, alpha-hederin and nigellicine [6]. It can be used to cure headache, nasal congestion, intermittent fever and dyspnea, and moreover, dried seeds can be used as inhalation to release cold. N. sativa components are used as immune-stimulatory and anti-inflammatory activity due tocytokines [7]. It is aninfluential, anti-inflammatory which inhibit the lipoxygenase and cyclooxygenase activities [8].

\subsubsection{Star anise}

The studies established a lot of medical uses mainly in sedative, antimicrobial and anti-inflammatory activities due to shikimic acid and flavonoid quercetin presence witch effected on mice intestinal muscles [9]. This is a multitalented plant that may be used for flu, treating respiratory tract blockage, lung swelling bronchitis, and whooping cough. Several medical activities as antispasmodic, aromatic, antiseptic and stimulant were shown by the essential oil [10]. Trans-anethol is also an essential component that can exhibit anti-viral properties [11].

\subsubsection{Olive oil}


In fact, quite a lot of reports have highlighted as anti-atherogenic and cardiovascular protective effects of olive oil or even olive due to the utmost flavonoids and phenolic acid bioactive compounds $[12,13]$. Inflammatory mediators consist of prostaglandin E2, nitric oxide, cytokines (IL-6, TNF- $\alpha$ ) which can develop some inflammatory diseases such as high fever and sepsis syndrome implicate [14].

\subsubsection{Argan oil}

Argan oil reports great levels of (g-tocopherol) the most effective antioxidant of tocopherols with highly (squalene) content which can delay or even prevent reactive oxygen species in plasma [15]. Current biochemical reports have exposed that fatty acids can modify the immune responses [16,17]. Definitely, cell mediated immunity, lymphocyte and lymphocyte-derived cytokine proliferation may be inclined by lipids on rats with obvious special effects on the function of immune cell [18].

\subsubsection{Sagebrush}

Sagebrush (Artemisia spp.) has been recognized in small amounts due to the anti-fungal, anti-parasitic and anti-bacterial activities [19]. Number polyphenols and phytochemicals as (ridentin, luteolin, aesculetins, antonin, quercetin, scopoletin, coumarin and apigenin) may act as biomarkers of biotic stresses [20]. Artemisia spp. is considered one of the medicinal plants that can be a promising alternative for a variety of diseases as human Immunodeficiency virus or (AIDS) with $2 \mu \mathrm{g} / \mathrm{ml}$ tea extract $[21,22]$.

\subsubsection{Basil oil}

Basil volatile oil comprises aldehydes, alkaloids, tannins, glycosides, phenols, saponins and terpenes with low amounts of $\beta$-carotene and vitamin C. Basil includes several essential oil such as eugenol, $\beta$-elemene, $\tau$-cadinol, $\tau$-muralol, $\alpha$-caryophyllene and $\alpha$-bisabolol [23]. Basils have been establish to be evidence against many bacterial, protozoal, fungal and specially viral infections. Moreover basil is proved to inhibit carcinogenic cells growth. O. basilicum has widespread uses of traditional medicine as headaches, colds, chest, lung problems, influenza, tonic, appetizer, expectorant, neuralgia, catarrh, fevers, coughs, asthma, influenza and bronchitis [24].

\subsubsection{Fennel}

Fennel seeds were establish to have highly antispasmodic, antioxidant, anti-inflammatory, antithrombotic, antiplatelet, antidementia activities [25]. Moreover, it play necessary role as pain reliever and immunity promoting against COVID-19 [26]. Beside a slight content of niacin, thiamine, riboflavin and ascorbic acid $[27]$.

\subsubsection{Garlic}

Garlic is used widely against many diseases. Allium sativum is used as anti-bacterial and antibiotic to destroy micro-organisms without any side effect for the natural flora in body. It is recommended to be as anticoagulant against clots formation in blood; antiseptic; anti-viral expectorant which promotes discharge mucous secretions in respiratory passages; febrifuge to help in reducing fevers and as stimulant that excites or even quickens tissues to generate additional energy [28].

\subsubsection{Peppermint oil}

Peppermint is an important herb widely used in various medicines like inflammatory diseases, analgesic, anesthetic, nervine, antiseptic, astringent, expectorant and decongestant. The oil is the main component of cough drops, ayurvedic medicines and ointments, that can be widely used for stomach disorders such as indigestion, gas, acidity treatments [29]. Moreover, to is highly suggested due to the effective anti-plasmid and antimicrobial activities. The essential oil is able to apply virucidal effect on (HSV) directly [30].

\section{Conclusion}

Eating balanced healthy diet, effective nutrients, hygiene precaution, firmly adhering to social separation, smoking refrain, accompanied by a simple exercise about 20-30 minutes daily can enhance the efficiency 
of immune system. Hence, all the potential interventions can be recommended to control the COVID-19 symptoms and infections.

\section{Conflicts of interest}

There are no conflicts to declare

\section{References}

1-Bennett BJ, Hall KD, Hu FB, McCartneyAL, Roberto C. Nutrition and the science of disease prevention: a systems approach to support metabolic health. Ann N Y Acad Sci. 2015; 1352:1-12.2

2-Haider IA, Sarmad GA, Hassan NH. The Effect of Nutrition on Immune System Review Paper. Food Science and Quality Management. 2019; 90: 31-53

3-Schoeman D, Fielding BC. Coronavirus envelope protein: current knowledge. Virol J. 2019;16(69): 1-22

4-Cohen J, Normile D. New SARS-like virus in China triggers alarm. Science.

2020;367:234-235

5-Zhu N, Zhang D, Wang W, et al. A novel coronavirus from patients withpneumonia in China. N Engl J Med. 2020;382(8):727-733

6-Randhawa MA, Alghamdi M.S. Anticancer activity of Nigella sativa (Black Seed) - a review. Am. J. Chin. Med. 2011;39 (6):1075-1091

7-Randhawa MA. An update on antimicrobial effects of Nigella sativa and experience at King Faisal University, Dammam, SaudiArabia. JSSDDS. 2008; 12 (1):36-43

8-Zafar K, Noorul H, Nesar A, Vartika S, Khalid M, Prashant S, Zeeshan A, Zohrameena S. Pharmacological Activity of Nigella Sativa: A Review. World Journal of Pharmaceutical Sciences. 2016; 234-241

9-Deng J, Huang L, XieY, Du Z, Hao E, Hou X. The anti-inflammatory and analgesic effects of star anise, an aromatic herb in South China. International Horticultural Congress on Horticulture: Sustaining Lives, Livelihoods and Landscapes (IHC2014): V World 1125, 2014; 1125(19): 151-160

10-Hanif MA, Al-MaskariMY, Al-MaskariA, Al-ShukailiA, Al-MaskariAY, Al-Sabahi JN. Essential oil composition, antimicrobial and antioxidant activities of unexplored Omani basil. Journal of Medicinal Plants Research. 2011; 5(5):751-757

11-Huang Y, Zhao J, Zhou L, Wang J, Gong Y, Chen X, Guo Z, Wang Q, Jiang W. Antifungal activity of the essential oil of Illicium verum fruit and its main component trans-anethole. Molecules. 2010; 15(11): 7558-7569

12-Escrich E, Solanas M, Moral R, Escrich R. Modulatory effects and molecular mechanisms of olive oil and other dietary lipids in breast cancer. Curr. Pharm. Des. 2011; 17(8): 813-830

13-Guasch-Ferré M, Hu FB, Martínez-González MA, Fitó M, Bulló M, Estruch R, Ros E, Corella D, Recondo J, Gómez-Gracia E. Olive oil intake and risk of cardiovascular disease and mortality in the PREDIMED Study. BMC Med. 2014; 12(78)p: 1-11

14-Munkyong P, Simin M,Dayong Wu. The Role of Nutrition in Enhancing Immunity in Aging. Aging and Disease. 2012; 3 (1): 91-129.

15-Khallouki F, et al. Thermal stability and long-chain fatty acid positional distribution on glycerol of argan oil. Food Chem. 2008; 110: 57-61

16-Harhar H, et al. Effect of argan kernel storage conditions on argan oil quality. Eur J Lipid Sci Technol. 2010; 112: 915-920 
17-Obolskiy D, et al. Garcinia mangostana L.: a phytochemical and pharmacological review. Phytother Res, 2009; 23: 1047-1065

18-Hanae E, Dom G, Clément D, Zoubida C. Therapeutic potential of argan oil: a review. Journal of Pharmacy and Pharmacology. 2010; 62: 1669-1675

19-Christopher RA,Christian AH,Katie MD, DwayneE. The effects of fire on the thermal environment of sagebrush communities. Journal of Thermal Biology. 2020; 89; 102488.

20-Xinzhu P, Lisa L, Kristina G, Amy C, Janet L, Jennifer S. Antioxidant capacity of wyoming big sagebrush (Artemisia Tridentata Ssp. Wyomingensis) varies spatially and is not related to the presence of a sagebrush dietary specialist. Hhs Public Access. 2015; 75(1): 78-87

21-Bahare S, Nanjangud V., Anil K, et al. Medicinal plants used in the treatment of human immunodeficiency virus. Int. J. Mol. Sci. 2018; 19, 1459:1-60

22-Umme L, Muhammad A, Mohammad A, et al. Role of medicinal plants in HIV/AIDS therapy. Clin Exp Pharmacol Physiol. 2019;46:1063-1073

23-Hanif MA, Al-Maskari MY, Al-Maskari A, Al-Shukaili A, Al-Maskari AY, Al-Sabahi JN. Essential oil composition, antimicrobial and antioxidant activities of unexplored Omani basil. Journal of Medicinal Plants Research.2011; 5:751-757

24-Lupton D, Mumtaz M., Al-Yahyai RA, Asif MH. Basil: A natural source of antioxidants and neutraceuticals. Leafy Medicinal Herbs: Botany, Chemistry, Postharvest Technology and Uses. 2016: 27-41

25-Fatiha O, Rachid S, Nadia E, Hakima B, Mustapha L, Souliman A, Noreddine G. Hypolipidemic and anti-atherogenic effect of aqueous extract of fennel (Foeniculum Vulgare) extract in an experimental model of atherosclerosis induced by triton WR-1339. Euro. J. of Scie. Res. 2011; 52(1):91-99

26-Barros L, Heleno SA, Carvalho AM, Ferreira IC. Systematic evaluation of the antioxidant potential of different parts of foeniculum vulgare mill. from Portugal. Food Chem. Toxicol. 2009; 47: 2458-2464

27-Amr AR. beneficial health effects of fennel seeds (Shamar) on male rats feeding high fat-diet. Med. J. Cairo Univ. 2012; 80(2): 101-113

28-SatyanandT, Patel C, Dadarwal P, Mangukia D, Sojitra I, Zubair KL, Anil KG, Kalpen NP. Importance of garlic (Allium sativum): an exhaustive review.2013; 1(4): 23-27

29-Reed JA. Jude A, Ben W, Bryan R.Effects of peppermint scent on appetite control and caloric intake. Appetite. 2008; 51(2):393-393

30-Schuhmacher A, ReichlingJ, Schnitzler P. Virucidal effect of peppermint oil on the enveloped viruses herpes simplex virus type 1 and type 2 in vitro. Phytomedicine.2003;10: 504-510 